\title{
CHF5074 (CSP-1103) INDUCES MICROGLIA ALTERNATIVE ACTIVATION IN PLAQUE-FREE TG2576 MICE AND PRIMARY GLIAL CULTURES EXPOSED TO BETA-AMYLOID
}

\author{
V. PORRINI, ${ }^{a, b}$ A. LANZILLOTTA, ${ }^{a}$ C. BRANCA, ${ }^{a}$ \\ M. BENARESE, ${ }^{a}$ E. PARRELLA, ${ }^{a}$ L. LORENZINI, \\ L. CALZÀ, ${ }^{c, d, e}$ R. FLAIBANI, ${ }^{b}$ P. F. SPANO, ${ }^{a, b}$ \\ B. P. IMBIMBO ${ }^{f}$ AND M. PIZZI ${ }^{a, b *}$ \\ ${ }^{a}$ Department of Molecular and Translational Medicine, University of \\ Brescia and National Institute of Neuroscience, Viale Europa 11, \\ 25123 Brescia, Italy \\ ${ }^{\mathrm{b}}$ IRCCS San Camillo Hospital, Via Alberoni 70, 30126 Venice, Italy \\ ${ }^{\mathrm{c}}$ Health Science and Technologies, Interdepartmental Center \\ for Industrial Research (HST-ICIR), University of Bologna, \\ Via Tolara di Sopra 41/E, 40064 Ozzano Emilia, Bologna, Italy \\ ${ }^{\mathrm{d}}$ Department of Pharmacy and Biotechnology, University of Bologna, \\ Via Tolara di Sopra 41/E, 40064 Ozzano Emilia, Bologna, Italy \\ e IRET Foundation, Via Tolara di Sopra 41/E, 40064 Ozzano \\ Emilia, Bologna, Italy \\ ${ }^{f}$ Research \& Development, Chiesi Farmaceutici, Via Palermo \\ 26/A, 43100 Parma, Italy
}

\begin{abstract}
Activation of microglia associated with neuroinflammation and loss of phagocytic activity is considered to play a prominent role in the pathogenesis of Alzheimer's disease (AD). CHF5074 (CSP-1103) has been shown to improve cognition and reduce brain inflammation in patients with mild cognitive impairment (MCl). CHF5074 was also found to reverse impairments in recognition memory and improve hippocampal long-term potentiation when administered to plaque-free $\mathrm{Tg} 2576$ mice (5-month-old) for 4 weeks. Though, no investigation has focused on the consequence of CHF5074 treatment on microglia polarization yet. In this study we evaluated the effect of CHF5074 administration (375 ppm in the diet) to 5-month-old Tg2576 mice on the expression of pro-inflammatory (M1) genes, Interleukin 1

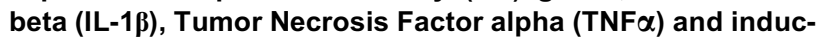
ible Nitric Oxide Synthase (iNOS), and anti-inflammatory/ phagocytic (M2) markers Mannose Receptor type C 1 (MRC1/CD206), Triggering Receptor Expressed on Myeloid
\end{abstract}

\footnotetext{
*Correspondence to: M. Pizzi, Department of Molecular and Translational Medicine, University of Brescia and National Institute of Neuroscience, Viale Europa 11, 25123 Brescia, Italy. Tel: +39-0303717501; fax: + 39-030-3717529.

E-mail address: marina.pizzi@unibs.it (M. Pizzi).

Abbreviations: $A \beta, \quad \beta$-amyloid; AD, Alzheimer's Disease; AICD, APP Intracellular Domain; APP, Amyloid Precursor Protein; ARG1, Arginase 1; CHF5074, 1-(3',4'-dichloro-2-fluoro[1,1'-biphenyl]-4-yl)cyclopropanecarboxylic acid; FIZZ1, Found in Inflammatory Zone; GSK-3 $\beta$, Glycogen Synthase Kinase-3 beta; IL-1 $\beta$, Interleukin 1 beta; iNOS, inducible Nitric Oxide Synthase; $\mathrm{MCl}$, Mild Cognitive Impairment; MRC1/CD206, Mannose Receptor type C 1; NSAID, Nonsteroidal Anti-Inflammatory Drugs; qRT-PCR, quantitative Retro TranscriptionPolymerase Chain Reaction; TNF $\alpha$, Tumor Necrosis Factor alpha; TREM2, Triggering Receptor Expressed on Myeloid Cells 2; Ym1, Chitinase 3-like 3.
}

cells 2 (TREM2) and Chitinase 3-like 3 (Ym1). No changes of pro-inflammatory gene transcription but a reduced expression of MRC1/CD206, TREM2 and Ym1 were detected in the hippocampus of young Tg2576 mice receiving normal diet, when compared to wild-type littermates. CHF5074 did not affect the pro-inflammatory transcription but significantly increased the expression of MRC1/CD206 and Ym1. CHF5074 effects appeared to be hippocampus-specific, as the M2 transcripts were only slightly modified in the cerebral cortex. In primary cultures of mouse astrocyte-microglia, CHF5074 totally suppressed the expression of TNF- $\alpha$, IL-1 $\beta$ and iNOS induced by $10 \mu \mathrm{M} \beta$-amyloid ${ }_{1-42}\left(A \beta_{42}\right)$. Moreover, CHF5074 significantly increased the expression of antiinflammatory/phagocytic markers MRC1/CD206 and TREM2, reduced by the $A \beta_{42}$ application alone. The effect of CHF5074 was not reproduced by ibuprofen $(3 \mu \mathrm{M}$ or $500 \mu \mathrm{M})$ or R-flurbiprofen ( $3 \mu \mathrm{M}$ or $100 \mu \mathrm{M})$, as both compounds limited the pro-inflammatory gene expression but did not modify the anti-inflammatory/phagocytic transcription. These data show that CHF5074 specifically drives the expression of microglia M2 markers either in young Tg2576 hippocampus or in primary astrocyte-microglia cultures, suggesting its potential therapeutic efficacy as microglial modulator in the early phase of $A D$.

This article is part of a Special Issue entitled: Inflammation in Nervous System Disorders (c) 2014 IBRO. Published by Elsevier Ltd. All rights reserved.

Key words: Alzheimer's disease, Tg2576, Neuroinflammation, Microglia, CHF5074, CSP-1103.

\section{INTRODUCTION}

Alzheimer's disease (AD) has a robust inflammatory component owing to the microglial response to fibrillar forms of $\beta$-amyloid $(A \beta)$ that are deposited in the diseased brain (Akiyama et al., 2000; Lucin and WyssCoray, 2009). Microglia, the brain tissue macrophages, are representatives of the innate immune system. Their exposure to $A \beta$ stimulates canonical host-defense mechanisms, resulting in the elaboration of an array of immune mediators including reactive oxygen and nitrogen species, chemokines and inflammatory cytokines. Microglial-mediated inflammation has been argued to be a critical contributor to $A D$ pathogenesis. Microglia number in the brain increases in proportion to the plaque dimension, possibly to regulate plaque dynamics through $A \beta$ clearance and phagocytosis. However, the 
accumulation of deposited forms of amyloid suggests that in $A D$ endogenous microglia are definitely insufficient or "impaired" in suppressing plaque formation (Grathwohl et al., 2009). The persistence of activated microglia and their secretion of pro-inflammatory cytokines and immune mediators contribute to the well-documented proinflammatory milieu in the $A D$ brain, which further acts to functionally inactivate the phagocytic machinery (Koenigsknecht-Talboo and Landreth, 2005).

The activation states of peripheral macrophage classified as M1 ("classically activated") or M2 ("alternatively activated"), have been recently proposed also to describe the dual phenotype acquired by activated microglia in the central nervous system (Boche et al., 2013). M1 activation is associated with the expression of pro-inflammatory molecule like Tumor Necrosis Factor alpha (TNF $\alpha$ ), Interleukin 1 beta (IL-1 $\beta$ ), inducible Nitric Oxide Synthase (iNOS), Interferon gamma. The M2 activation state is related to the production of anti-inflammatory cytokines and markers of phagocytosis. It is characterized by expression of genes like Mannose Receptor type C 1 (MRC1/CD206), a cell surface receptor involved in antigen recognition and presentation as well as in phagocytosis of macrophages (Colton et al., 2006), and Arginase 1 (ARG1) involved in mechanism of protection and repair of the extracellular matrix (Colton et al., 2006). Among M2 genes associated with tissue remodeling, there are Found in Inflammatory Zone (FIZZ1) and Chitinase 3-like 3 (Ym1), the mammalian lectin associated with reconstruction of extracellular matrix by binding heparan sulfate (Colton, 2009). Lastly, Triggering Receptor Expressed on Myeloid cells 2 (TREM2) is a member of the innate immune receptor TREM family which enhances phagocytosis by microglia (Piccio et al., 2007). TREM2 could be relevant to the removal of cell debris as well as the clearance of amyloid proteins in AD, (Piccio et al., 2007; Takahashi et al., 2007; Frank et al., 2008) and suppression of inflammatory response, including cytokine production and secretion. The phagocytic profile of microglia is also crucial in the "resting" condition, during which they continuously survey the brain environment by extending and retracting their processes. It has been demonstrated that microglia can eliminate synaptic elements, neuronal precursors, and redundant newborn cells during adult neurogenesis (Sierra et al., 2010). Beside enabling synaptic pruning (Paolicelli et al., 2011), microglia modulate synaptic activity and plasticity (Moriguchi et al., 2003) and are fundamental in experience-mediated remodeling of neuronal circuits in diseased and healthy brain (Nimmerjahn et al., 2005; Wake et al., 2009; Rogers et al., 2011; Tremblay et al., 2010, 2012; Schafer et al., 2012; Bechade et al., 2013; Sogn et al., 2013; Ji et al., 2013; Zhan et al., 2014).

CHF5074 (CSP-1103), 1-(3',4'-dichloro-2-fluoro[1,1'-biphenyl]-4-yl)cyclopropanecarboxylic acid, has been recently shown to bind and inhibit amyloid precursor protein (APP) intracellular domain (AICD) (Branca et al., 2014). CHF5074 actively lowers plaque burden in the hippocampus and cortex of AD mice (Imbimbo et al., 2007a, 2009). It reduces cognitive deficits and microglial activation in adult TASD-41 (Imbimbo et al., 2009) and aged Tg2576 transgenic mice (Sivilia et al., 2013) when administered at 6 months of age (375 ppm in the diet), respectively for 6 and 13 months. The beneficial effects of CHF5074 on memory in aged AD mice were found to be associated with partial resolution of microglia immunoreactivity around the plaques. Additional studies demonstrated that even administered in a subchronic way (4-week), CHF5074 can fully reverse recognition memory impairment in young, plaque-free Tg2576 mice. In 5-month-old Tg2576 mice CHF5074 treatment rescued long-term potentiation in the hippocampus and decreased hyperphosphorylated tau without affecting soluble or oligomeric brain A $\beta$ levels (Balducci et al., 2011). Eight-day treatment with CHF5074 also restored cortical acetylcholine release (Giuliani et al., 2013) and regulated extracellular glutamate levels (Beggiato et al., 2014) in pre-plaque Tg2576 mice. So far no information exists about the microglia activation state in young Tg2576, as well as the impact of CHF5074 treatment on early presumed microglia changes. Though clinical studies in healthy subjects (Imbimbo et al., 2013) and in patients with mild cognitive impairment (MCl) (Ross et al., 2013) showed that CHF5074 can dose-dependently reduce CSF levels of TNF $\alpha$ and SCD40L. As CHF5074 did not cause any concomitant change in the CSF level of $A \beta$, the reduction of neuroinflammatory biomarkers in humans appears to occur independently from any effect on $\gamma$-secretase activity.

The aim of the present study was to evaluate the microglial expression profile in young, plaque-free Tg2576 mice and the modulatory activity of CHF5074 treatment either in mice or in primary mixed astrocytemicroglia cultures exposed to $\beta$-amyloid - $_{1-42}\left(A \beta_{42}\right)$.

\section{EXPERIMENTAL PROCEDURES}

\section{Primary cell culture}

C57BL/6 mice were purchased from Charles River, Wilmington, MA, USA. Mixed glial cell cultures were prepared from the brains of 1-3-day newborn mice. Briefly, after carefully removing meninges and large blood vessels, the brains were pooled and then dissociated by manual dispersion with a fire-polished Pasteur pipette. The cells were allowed to attach and grow at $37^{\circ} \mathrm{C}$ in DMEM supplemented with $10 \%$ fetal bovine serum (FBS) (Euroclone, Milan, Italy), $4 \mathrm{mM}$ L-glutamine, $200 \mathrm{U} / \mathrm{ml}$ penicillin/streptomycin in a water saturated atmosphere containing $5 \% \mathrm{CO}_{2}$ for 14 days. $\mathrm{A}$ near $10 \%$ of microglia was present in the mixed microglia-astrocyte cultures.

\section{Beta-amyloid toxicity}

Soluble $A \beta_{42}$ (Life Technologies, Monza, Italy) were dissolved in sterile water to a final concentration of $2.5 \mathrm{mM}$, divided into aliquots and frozen.

For experiments, mixed glial cells were incubated with soluble (not aggregated) $A \beta_{42}$, added at a concentration of $10 \mu \mathrm{M}$, in the presence of CHF5074 $3 \mu \mathrm{M}$ (Chiesi Farmaceutici, Parma, Italy), Ibuprofen $3 \mu \mathrm{M}$ and $500 \mu \mathrm{M}$ 
(Sigma-Aldrich, St. Louis, MO, USA), R-Flurbiprofen $3 \mu \mathrm{M}$ and $500 \mu \mathrm{M}$ (Chiesi Farmaceutici) (solved in $0.2 \%$ dimethyl sulfoxide) or vehicle. Incubations were carried out for different times (from 1 to 8 days) in DMEM medium. At the end of these periods, total RNA was isolated and retro-transcripted to cDNA for real-time quantitative retro transcription-polymerase chain reaction (qRT-PCR) analysis.

\section{Animals and treatments}

The Tg2576 transgenic mouse carries a transgene coding for the 695-amino acid isoform of human APP derived from a large Swedish family with early-onset AD (Hsiao et al., 1996). Five-month-old female Tg2576 mice and age-matched wild-type littermates were used. Mice ( $n=10$ per Tg2576 treatment group, $n=10$ per wildtype) were treated for 4 weeks with CHF5074 (375 ppm in the diet, corresponding to approximately $60 \mathrm{mg} / \mathrm{kg} /$ day) or with standard diet. Animal care and treatments were in accordance with European Community Council directives (86/609/EEC) and in conformity with protocols approved by ethics committee for animal experimentation of University of Bologna ( $n$. 72, October 01, 2012). At the end of treatment, mice were sacrificed by cervical dislocation. Their brains were removed, the hippocampus and cerebral cortex were dissected and immediately frozen to be subsequently processed for RNA extraction.

\section{Real-time quantitative reverse transcription- polymerase chain reaction (qRT-PCR)}

Total RNA was purified from cells and tissues using the RNeasy Mini Kit for total RNA extractions (Qiagen, Valencia, CA, USA). RNA was reverse transcribed using the Quantitect ${ }^{\circledR}$ Reverse Transcription Kit (Qiagen) with optimized mix of oligo-dT and random primers as primer and $1 \mu \mathrm{g}$ of total RNA from mixed glial cultures and cortical and hippocampal tissues. The reverse transcription reaction comprised 2 main steps: elimination of genomic DNA and reverse transcription. In the first step, $1 \mu \mathrm{g}$ of total RNA was added to $7 \times$ gDNA Wipeout Buffer resuspended in RNAse-DNase free water (final volume of $14 \mu \mathrm{l}$ ) and briefly incubated at $42{ }^{\circ} \mathrm{C}$ for $2 \mathrm{~min}$ to effectively remove contaminating genomic DNA. After genomic DNA elimination, a mix of $5 \times$ Quantiscript RT Buffer, that included dNTPs and $\mathrm{Mg}^{2+}$, Quantiscript Reverse Transcriptase, that also contained RNase inhibitor, and RT Primer Mix was added to the RNA sample to reach a final volume of $20 \mu \mathrm{l}$. The entire reaction was incubated at $42{ }^{\circ} \mathrm{C}$ for $15 \mathrm{~min}$ and was then inactivated at $95^{\circ} \mathrm{C}$ for $3 \mathrm{~min}$. Retrotranscribed cDNA was amplified in $25 \mu \mathrm{l}$ SYBR Green real-time PCR reactions containing 2-8 $\mu$ l of cDNA, $12.5 \mu$ of $2 \times \mathrm{iQ}^{\text {TM }}$ SYBR Green Supermix (BioRad, Hercules, CA, USA), and $1 \mu$ of each $10 \mu \mathrm{M}$ optimized forward and reverse primers in 8.5-2.5 $\mu \mathrm{l}$ RNase-free water. PCR reaction was performed using a 3-stage program: $3 \mathrm{~min}$ at $50^{\circ} \mathrm{C}, 10 \mathrm{~min}$ at $95^{\circ} \mathrm{C}$ and 40 cycles of $30 \mathrm{~s}$ at $94^{\circ} \mathrm{C}$ and $45 \mathrm{~s}$ at $60^{\circ} \mathrm{C}$. Incorporation of the SYBR Green dye into the PCR products was monitored in real-time with a BIORAD iCycler detection system, allowing the determination of the threshold cycle (CT) at which the exponential amplification of PCR products began. Each reaction was performed in triplicate. For standardization of quantification, $\beta$-actin was amplified simultaneously.

\section{Western blot analyses}

Brain lysates from hippocampi of WT and Tg mice and immunoblot analyses were carried out as previously described (Lanzillotta et al., 2011).

Total extracts $(50 \mu \mathrm{g}$ proteins/sample) were suspended in the sample-loading buffer and resolved by 4-12\% SDS/polyacrylamide gel. Immunodetection was performed by incubating the membrane overnight at $4{ }^{\circ} \mathrm{C}$, with the following primary antibodies: anti$\beta$ III-tubulin rabbit antibody (1:2000; Sigma-Aldrich); anti-phospho-GSK-3 $\beta$ (Ser9) rabbit antibody (1:1000; Cell Signaling, Danvers, MA, USA), which identify the inactivated kinase; anti-GSK-3 $\beta$ rabbit antibody (1:1000; Cell Signaling). Quantification of protein expression was performed by densitometry analysis of immunoblots, using GelPro analysis software. Each protein band was normalized to the relative $\beta$ III-tubulin signal.

\section{Statistical analysis}

Data were analyzed with Student's t-test for independent data or with a 2-way ANOVA (with genotype and treatment as fixed factors), followed by the Holm-Sidak test for multiple comparison. Data are presented as mean \pm SEM. $P<0.05$ was considered as significant.

\section{RESULTS}

\section{Subchronic treatment with CHF5074 reduces microglia anti-inflammatory/phagocytic transcription in the hippocampus of 5-month-old Tg2576 mice}

As previously described (Balducci et al., 2011), 5-monthold female Tg2576 mice were treated with CHF5074medicated diet or normal diet for 4 weeks. After treatment, mice were sacrificed and the hippocampus and cerebral cortex tissues processed for real-time qRT-PCR analysis of mRNA expression.

To investigate classical pro-inflammatory transcripts we analyzed TNF $\alpha, \mathrm{IL}-1 \beta$ and iNOS mRNAs. As markers of "alternative" microglial activation we investigated TREM2, MRC1/CD206, and Ym1. TNF $\alpha$ was nearly undetectable in all experimental groups (data not shown) and no difference in the expression levels of IL-1 $\beta$ and iNOS was found among wild-type and Tg2576 mice treated with either vehicle or CHF5074 (Fig. 1A). Conversely, when compared to wild-type littermates, Tg2576 mice displayed a significant lower expression of TREM2 and MRC1/CD206 together with a trend to a lower expression for Ym1 in the hippocampus (Fig. 1B). Treatment with CHF5074 significantly increased two of the three M2 markers. It restored the expression of MRC1/CD206 and induced the expression of Ym1, while it did not modify the level of TREM2 mRNA. The changes in M2 anti-inflammatory/phagocytic markers appeared to be hippocampus-specific as the cerebral 
Hippocampus

A

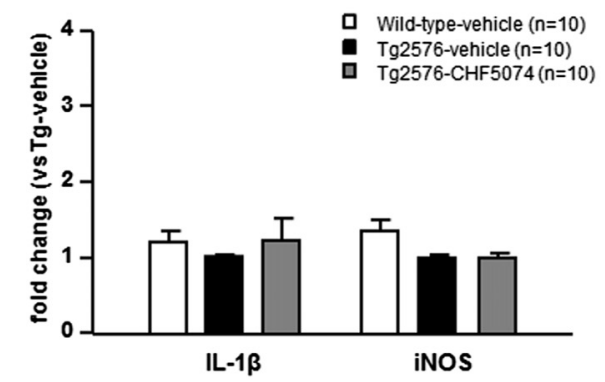

B

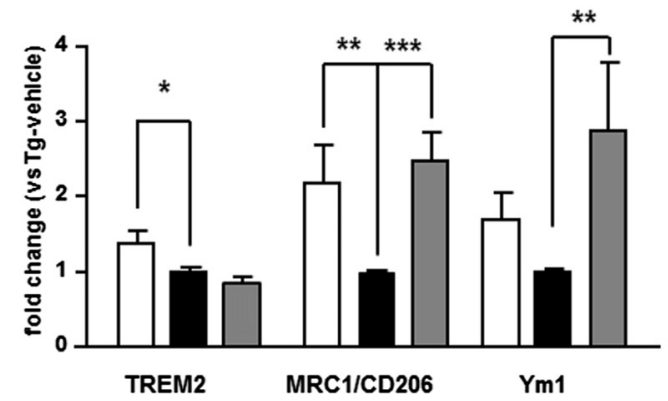

\section{Cerebral cortex}

C

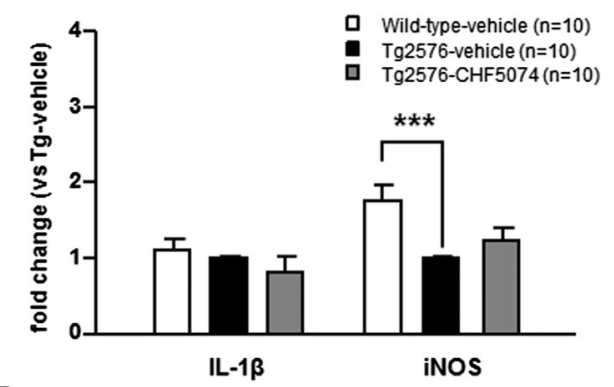

D

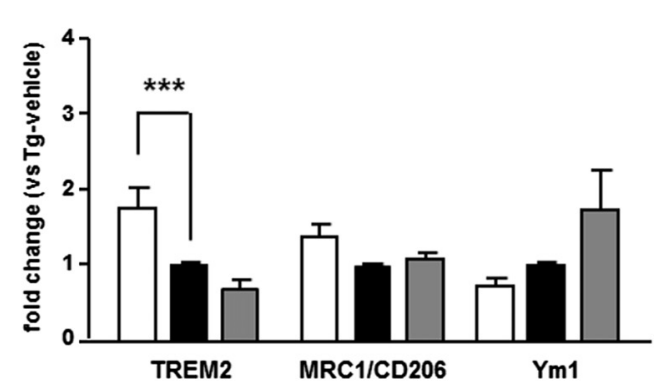

Fig. 1. Effect of CHF5074 on pro-inflammatory and anti-inflammatory/phagocytic transcripts in the hippocampus and cerebral cortex of 5-month-old Tg2576 mice. (A) Evaluation of IL-1 $\beta$ and iNOS mRNAs by qRT-PCR in the hippocampus. Expression of IL-1 $\beta$ and iNOS was similar in Tg2576 mice and wild-type mice. No change was produced by CHF5074 subchronic treatment in Tg2576 mice. (B) Measurement of TREM2, MRC1/CD206 and Ym1 mRNA levels by qRT-PCR in the hippocampus. Lower expression of TREM2 and MRC1/CD206 was detected in Tg2576 mice when compared to wild-type mice. Ym1 showed a trend to decrease in Tg2576. Subchronic treatment with CHF5074 increased the expression of MRC1/CD206 and Ym1, whereas it did not change the expression of TREM2. (C) Evaluation of IL-1 $\beta$ and iNOS expression by qRT-PCR in cerebral cortex. iNOS mRNA was reduced and IL-1 $\beta$ was not modified in Tg2576 mice compared to wild-type mice. No significant effect was produced by $\mathrm{CHF} 5074$ treatment. (D) Analysis of TREM2, MRC1/CD206 and Ym1 mRNA levels in cerebral cortex. A significant decrease of TREM2 mRNA but no change in MRC1/CD206 and Ym1 expression was detected in Tg2576 mice. CHF5074 treatment did not affect the expression of the M2 markers $\left({ }^{*} p<0.05,{ }^{* *} p<0.01,{ }^{* * *} p<0.001\right.$; two-way ANOVA followed by Holm-Sidak test for comparison vs Tg2576 Vehicle group).

cortex displayed only a minor reduction of TREM2 (Fig. 1D) and iNOS (Fig. 1C). Both modifications were unresponsive to CHF5074 treatment.

Analogous experimental treatment in plaque-free Tg2576, showed the capability of CHF5074 to reduce both cerebral hyper-phosphorylated and total tau (Balducci et al., 2011), an important target of glycogen synthase kinase-3 beta (GSK-3 $\beta$ ) in AD (Lanzillotta et al., 2011). As a neurochemical parameter of CHF5074 effect in the brain, we measured the hippocampal levels of total GSK-3 $\beta$ and the inactive GSK-3 $\beta$ phosphorylated (pSer9) form. In line with previous evidence obtained in TASD-41 AD mice (Lanzillotta et al., 2011), CHF5074 treatment decreased the GSK-3 $\beta$ total amount without affecting the $p-G S K-3 \beta / G S K-3 \beta$ ratio (data not shown).

\section{$A \beta_{42}$ induces expression of pro-inflammatory cytokines and reduces microglia anti-inflammatory/ phagocytic transcription in astrocyte-microglia cultures}

To investigate the activity of CHF5074 in modulating microglial activation independently from interaction with neuronal or circulating factors we adopted the cell-based model of mixed astrocyte-microglia cultures exposed to $A \beta_{42}$.

Astrocyte-microglia cultures were exposed to $10 \mu \mathrm{M}$ concentration of soluble $A \beta_{42}$ and the RNA was isolated at different time-points, i.e. 1, 2, 3 and 8 days after $A \beta_{42}$ addition (Fig. 2). By qRT-PCR we analysed the expression of $\mathrm{IL}-1 \beta$ and TNF $\alpha$, as markers of $\mathrm{M} 1$ microglial activation, and MRC1/CD206 as a marker of phagocytic M2 microglia activation (Town et al., 2005; Mosser and Edwards, 2008; Martinez et al., 2009). No expression change was detected at day 1, but a major pro-inflammatory activation of microglia was measured 2 days after $A \beta_{42}$ addition. The expression of IL-1 $\beta$ (Fig. 2A) and TNF $\alpha$ (Fig. 2B) markedly increased, while expression of MRC1/CD206 decreased (Fig. 2C). These changes were less evident 3 days after the $A \beta_{42}$ addition and totally disappeared after 8 days of treatment.

\section{CHF5074 reduces pro-inflammatory transcription and increases microglia anti-inflammatory/phagocytic transcription in astrocyte-microglia cultures exposed to $A \boldsymbol{\beta}_{42}$}

We examined the effect of CHF5074 on the inflammatory response induced by $A \beta_{42}$. Mixed cultures of 

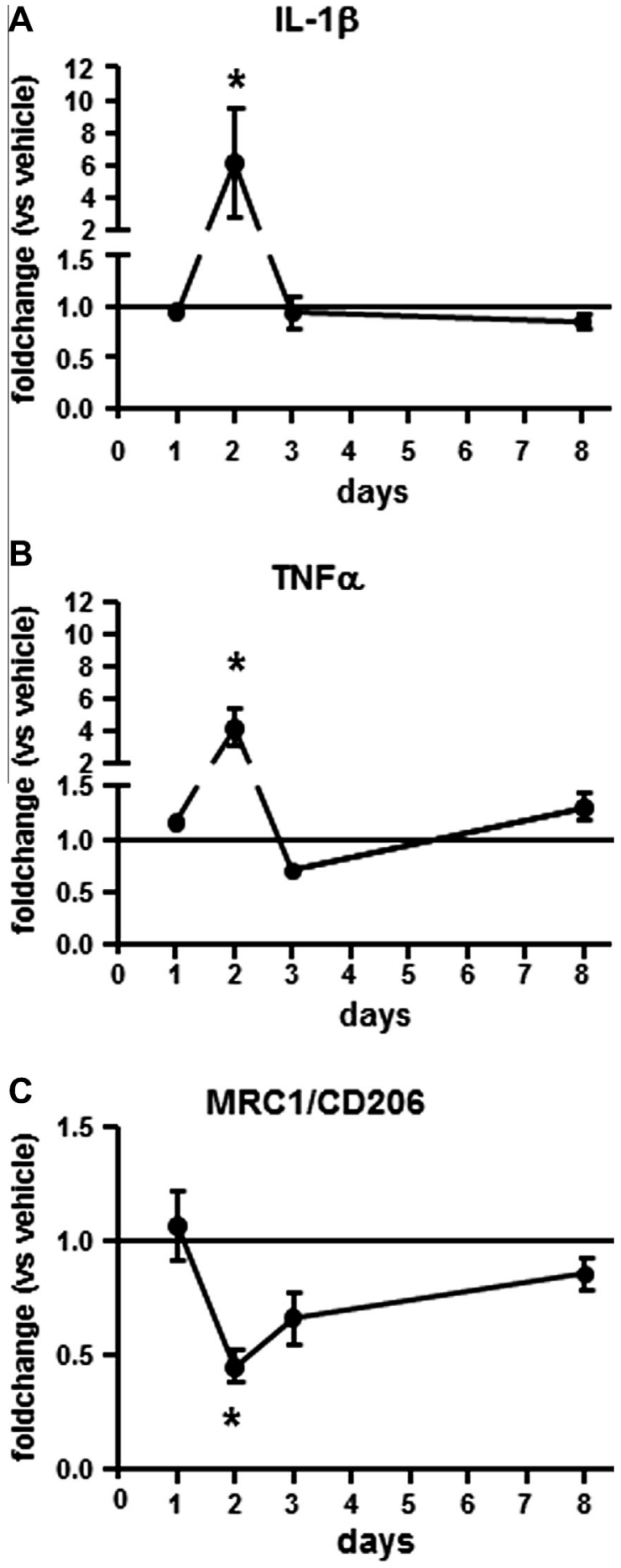

Fig. 2. Evaluation of $A \beta_{42}$ treatment on $M 1$ and $M 2$ markers levels in astrocyte-microglia cultures. Astrocyte-microglia cultures' exposure to $A \beta_{1-42}\left(A \beta_{42}\right)$ for $1,2,3$ or 8 days induced the expression of proinflammatory cytokines IL-1 $\beta(A)$ and TNF $\alpha(B)$, but depressed the expression of MRC1/CD206 $(C)$, as measured by qRT-PCR. Changes in expression levels were maximal after 2 days of $A \beta_{42}$ exposure and fall down at 8 days. $\left({ }^{*} p<0.05\right.$; Student's $t$-test for independent data for comparison vs corresponding vehicle).

astrocyte-microglia were exposed to $A \beta_{42}$ with or without CHF5074 at $3 \mu \mathrm{M}$, a concentration reproducing the brain levels of CHF5074 measured after administration of CHF5074-medicated diet (375 ppm) in TASD-41 mice
(Imbimbo et al., 2009). Cultures were examined for cytokine expression after 2 or 8 days (Fig. 3). The expression of iNOS, as well as TNF $\alpha$ and IL-1 $\beta$, increased after 2-day-treatment with $A \beta_{42}$, confirming the ability of $A \beta_{42}$ to induce the pro-inflammatory response in mixed glial cultures. Co-exposure to CHF5074 decreased IL-1 $\beta$ as well as TNF $\alpha$, and iNOS mRNA expression (Fig. 3A).

We also investigated alternative microglial activation markers in mixed glial cultures exposed to $A \beta_{42}$ with and without CHF5074 for 2 days or 8 days (Fig 3B, D). We checked the mRNA expression of MRC1/CD206 with TREM2 and, being undetectable the expression of Ym1 in cultured cells (data not shown), we included ARG1. Two-day exposure to $A \beta_{42}$ significant reduced the MRC1/CD206 expression by about $50 \%$ of basal value (Fig. 3B). This effect was reversed by CHF5074 which produced a near threefold increase of MRC1/ CD206 mRNA level. $A \beta_{42}$ treatment did not affect TREM2 expression per se, but CHF5074 significantly increased TREM2 mRNA by near $60 \%$ over the basal level. No change of ARG1 expression was detected in primary cultures at any condition tested (Fig. 3B). After 8 days of $A \beta_{42}$ treatment, $M 1$ and $M 2$ mRNAs returned to the basal values and CHF5074 addition was unable to induce any further change (Fig. 3C, D).

Chemically, CHF5074 is a nonsteroidal antiinflammatory drugs (NSAID) derivative but it is devoid of inhibitory activity on cyclooxygenase up to $300 \mu \mathrm{M}$ concentrations (Imbimbo et al., 2007b). We then investigate whether CHF5074 modulatory effects on microglia transcription were reproduced by NSAIDs, the cyclooxygenase inhibitor ibuprofen, or the NSAID derivative R-flurbiprofen devoid of cyclooxygenase inhibitory activity. Astrocyte-microglia cultures were exposed for 2 days to $\mathrm{A} \beta_{42}$ with or without ibuprofen at $3 \mu \mathrm{M}$ and $500 \mu \mathrm{M}$, or with R-flurbiprofen at $3 \mu \mathrm{M}$ and $100 \mu \mathrm{M}$ (Fig. 4). In line with previous evidence showing anti-inflammatory activity of the NSAID (Stratman et al., 1997), either ibuprofen of R-flurbiprofen significantly reduced the iNOS expression during $A \beta_{42}$ exposure (Fig. 4A). Conversely neither ibuprofen nor R-flurbiprofen increased the expression of anti-inflammatory/phagocytic markers TREM2 and MRC1/CD206 (Fig. 4B, C).

\section{DISCUSSION}

This study shows that CHF5074 can act as a microglia modulator, able to polarize microglia from the "proinflammatory M1" to the "alternative M2" phenotype.

In mouse mixed glial cultures, $A \beta_{42}$ exposure induced the pro-inflammatory expression of TNF $\alpha, \mathrm{IL}-1 \beta$ and iNOS and reduced the expression of MRC1/CD206, a marker of the anti-inflammatory/phagocytic activation state of microglia. The effect peaked at two days and fell to basal level at 8 days. CHF5074 co-exposure limited the pro-inflammatory $M 1$ gene expression and increased mRNA levels of M2 microglia markers MRC1/ CD206 and TREM2. These data, obtained in a cellbased model of $A \beta$-induced neuroinflammation, indicate that CHF5074 can directly modulate the phenotype of active microglia, independently of the interaction with 

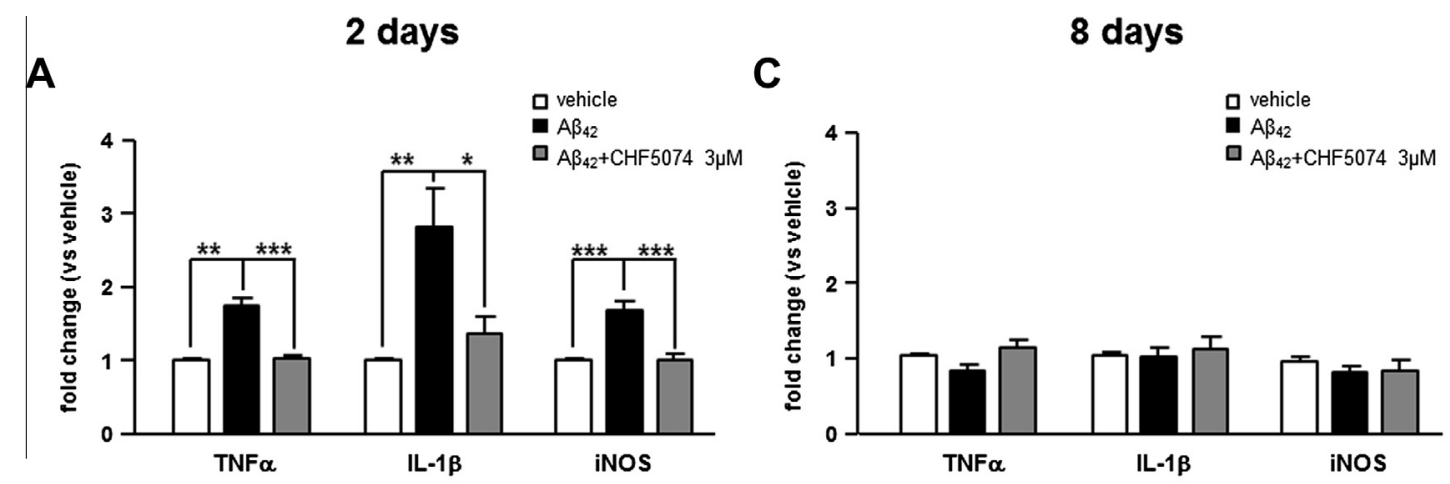

B
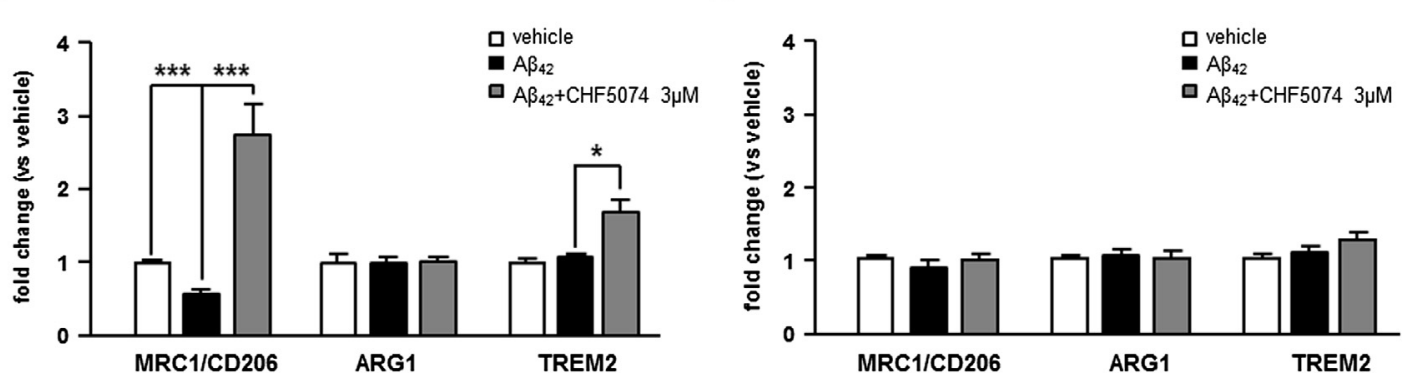

Fig. 3. Effects of CHF5074 on expression of pro-inflammatory and anti-inflammatory/phagocytic markers in astrocyte-microglia cultures exposed to $\mathrm{A} \beta_{42}$. (A) qRT-PCR analysis of TNF $\alpha, \mathrm{IL}-1 \beta$ and iNOS expression in astrocyte-microglia cultures exposed to $10 \mu \mathrm{M}$ A $\beta_{42}$. Two days exposure of cells to $3 \mu \mathrm{M}$ CHF5074 decreased the $A \beta_{42}$-induced expression of pro-inflammatory cytokines TNF $\alpha$, IL- $1 \beta$ and iNOS (B) qRT-PCR analysis of MRC1/CD206, ARG1 and TREM2 expression in astrocyte-microglia cultures exposed to $A \beta_{42}$ for 2 days. Addition of $3 \mu \mathrm{M}$ CHF5074 increased the MRC1/CD206 and TREM2 expression reduced by $A \beta_{42}$. No change was observed in ARG1 expression level (C) TNF $\alpha$, IL-1 $\beta$ and iNOS expression in cells exposed to $A \beta_{42}$ with or without CHF5074 for 8 days. Neither $A \beta_{42}$ alone nor in combination with CHF5074 modify the microglia activation state. (D) Quantification of MRC1/CD206, ARG1 and TREM2 expression in cells exposed to $A \beta_{42}$ with or without CHF5074 for 8 days. No changes in gene expression are observed in cultures exposed to $A \beta_{42}$ alone or and in the presence of CHF5074. $\left({ }^{*} p<0.05,{ }^{* *} p<0.01\right.$, ${ }^{* * *} p<0.001$; Student's $t$-test for independent data for comparison vs corresponding $A \beta_{42}$ ).

A

iNOS

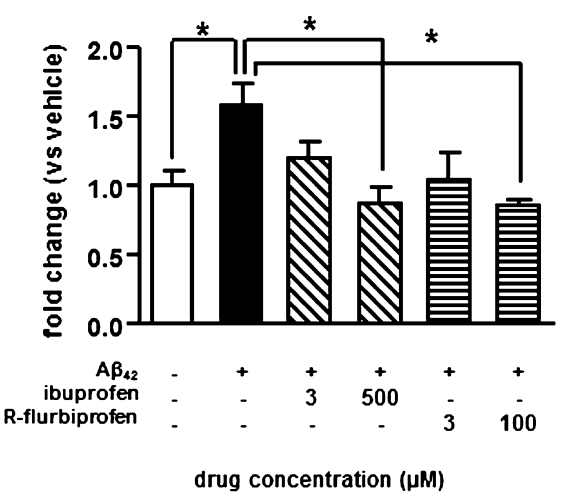

B

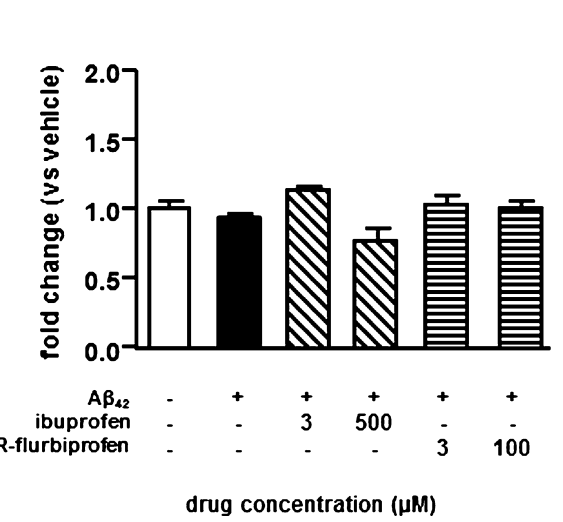

C

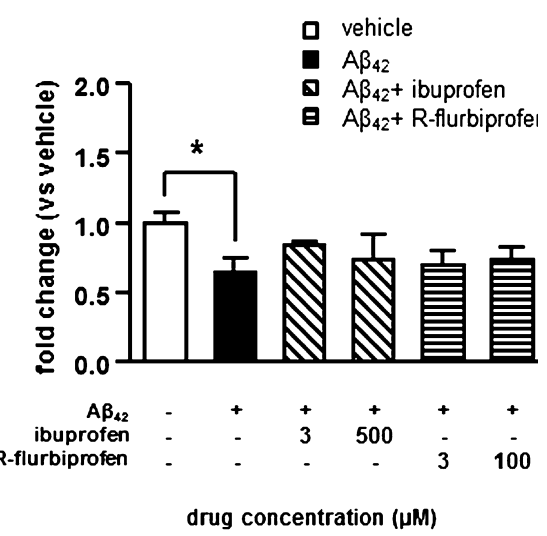

Fig. 4. Effects of ibuprofen and R-flurbiprofen on expression of pro-inflammatory and anti-inflammatory/phagocytic markers in astrocyte-microglia cultures exposed to $A \beta_{42}$. Two days exposure of astrocyte-microglia cultures to ibuprofen ( $3 \mu \mathrm{M}$ or $\left.500 \mu \mathrm{M}\right)$ and R-Flurbiprofen ( $3 \mu \mathrm{M}$ or $\left.100 \mu \mathrm{M}\right)$, in the presence of $10 \mu \mathrm{M} \mathrm{A} \beta_{42}$, reduced the expression of iNOS (A). Neither ibuprofen nor R-flurbiprofen affected the expression level of TREM2 (B) and MRC1/CD206 (C) $\left({ }^{*} p<0.05\right.$; Student's $t$-test for independent data for comparison vs corresponding $\left.A \beta_{42}\right)$.

neuronal or circulating cells and apart from modulation of $A \beta$ generation. The results are also in line with previous clinical evidence showing that CHF5074 administration reduces TNF $\alpha$ levels in cerebrospinal fluid of healthy subjects (Imbimbo et al., 2013) and of $\mathrm{MCl}$ patients (Ross et al., 2013). Worth of note, the peculiar modulation of M2 microglial transcription by CHF5074 in primary cultures was not reproduced by the classical NSAID ibuprofen or by the atypical NSAID R-flurbiprofen devoid of cyclooxygenase inhibitory activity (Morihara et al., 2002). In line with previous evidence (Ogawa et al., 2000; Hinz et al., 2000; Heneka et al., 2005), either ibuprofen or R-flurbiprofen diminished iNOS mRNA, but neither compound modified MRC1 or TREM2 expression. 
Recently, it has been published that heterozygous lossof-function mutations in TREM2 gene are associated with a significant increase in the risk of $A D$ (Guerreiro et al., 2013). This evidence has enormously emphasized the role of microglia alternative activation in the pathogenesis of AD. It was suggested that drugs modulating inflammation by switching the activation state of microglia toward the M2 state, rather than totally repressing microglia reactivity, might make a good therapeutic.

We thus investigated the capability of CHF5074 to modulate microglial transcription in $A D$ mice. Previous studies in Tg2576 mice showed that the inflammatory M1 expression is present only at later stages of disease, from 13 months onward (Kotilinek et al., 2008), and that at 18 months of age both M1 and M2 markers are expressed (Colton et al., 2006). Though, no evidence exists about the expression level of M2 markers at the earliest stage of disease (6 months of age) when, in the absence of amyloid plaque accumulation, Tg2576 mice already display cognitive deficits and impairment of hippocampal synaptic plasticity (Jacobsen et al., 2006; Balducci et al., 2011). We originally demonstrated that the expression of microglia anti-inflammatory/phagocytic markers TREM2, MRC1/CD206 and Ym1 is significantly reduced in the brain of 6-month-old Tg2576 mice, while the expression of pro-inflammatory IL-1 $\beta$ and iNOS is unchanged. Treatment with CHF5074 efficiently reverses the depression of two of the three M2 markers, MRC1/ CD206 and Ym1. A body of evidence proves the pivotal role of microglial phagocytosis in structural remodeling of neuronal circuits and in modulation of synaptic activities and plasticity (Sierra et al., 2010; Tremblay et al., 2010; Schafer et al., 2012; Tremblay et al., 2012). We here report that cognitive defects in young Tg2576 mice, i.e., reduced contextual and recognition memory and decreased synaptic plasticity in the hippocampus (Jacobsen et al., 2006; Balducci et al., 2011), are temporally associated with "reduced or impaired" transcription in anti-inflammatory/phagocytic microglia. Pharmacological intervention through subchronic administration of CHF5074, limiting memory deficits and synaptic dysfunction in young Tg2576 mice (Balducci et al., 2011), switches on the transcriptional activity of phagocytic microglia.

Worth of note, this switch was found in the hippocampus, the brain structure primarily involved in spatial and recognition memory and one of the first regions affected in AD. Changes in microglial transcription were less evident in cerebral cortex of young Tg2576 mice and consequently the effect of CHF5074 was much weaker there.

The mechanism by which CHF5074 can induce microglia "alternative" transcription remains to be explored yet. Both CHF5074 and ibuprofen have been shown to lower the GSK-3 $\beta$ level (Lanzillotta et al., 2011), an effect that could contribute to their common activity in reducing the expression of proinflammatory cytokines and iNOS (Martin et al., 2005; Green and Nolan, 2012) in primary astrocyte-microglia exposed to $A \beta_{42}$. Though, alternative pathways differentiating CHF5074 from ibuprofen or R-flurbiprofen in switching microglia polarization, deserve to be investigated. Among possible mechanisms, AICD-dependent effects targeted by CHF5074 (Branca et al., 2014), but still unexplored in glial cells, should be taken into consideration.

While in the past neuroinflammation was considered simply an epiphenomenon of $A D$, now it is rapidly being recognized as a crucial step in the $A D$ pathogenesis. This hypothesis has been bolstered by recent genomewide association studies that have uncovered microglial TREM2, Complement Receptor 1, and Cluster of differentiation 33 as key $A D$ risk genetic factors (Zhang et al., 2013). The old approach of achieving broad suppression of inflammation with NSAIDs has not produced positive results for either treatment (Imbimbo et al., 2010) or prevention of AD (The Alzheimer's Disease Anti-inflammatory Prevention Trial Research Group, 2013). One possible explanation for this is that modulating neuroinflammation, rather than suppressing it, may ultimately prove to be the most beneficial strategy against AD. CHF5074 might represent an innovative approach for balancing neuroinflammation in the $A D$ brain.

\section{CONTRIBUTIONS}

V.P. and M.P. conceived and designed the experiments. V.P., A.L., C.B., M.B., E.P. and R.F. performed the experiments. L.L. and L.C took care of Tg2576 mice handling and treatment. B.P.I. contributed to data analysis and paper revision. PF.S., M.P. and V.P. discussed the data and wrote the paper.

All the authors read and approved the final article.

\section{CONFLICT OF INTERESTS}

Bruno P. Imbimbo is an employee of Chiesi Farmaceutici that partially supports this study. The other authors declare no conflict of interest.

Acknowledgments-This work was co-funded by Chiesi Farmaceutici, Parma, Italy and by the Italian Ministry of Health (Grant 2603142).

\section{REFERENCES}

Akiyama H, Barger S, Barnum S, Bradt B, Bauer J, Cole GM, Cooper NR, Eikelenboom $\mathrm{P}$, Emmerling $\mathrm{M}$, Fiebich $\mathrm{BL}$, Finch $\mathrm{CE}$, Frautschy S, Griffin WS, Hampel H, Hull M, Landreth G, Lue L, Mrak R, Mackenzie IR, McGeer PL, O'Banion MK, Pachter J, Pasinetti G, Plata-Salaman C, Rogers J, Rydel R, Shen Y, Streit W, Strohmeyer R, Tooyoma I, Van Muiswinkel FL, Veerhuis R, Walker D, Webster S, Wegrzyniak B, Wenk G, Wyss-Coray T (2000) Inflammation and Alzheimer's disease. Neurobiol Aging 21:383-421.

Balducci C, Mehdawy B, Mare L, Giuliani A, Lorenzini L, Sivilia S, Giardino L, Calzà L, Lanzillotta A, Sarnico I, Pizzi M, Usiello A, Viscomi AR, Ottonello S, Villetti G, Imbimbo BP, Nisticò G, Forloni G, Nisticò R (2011) The $\gamma$-secretase modulator CHF5074 restores memory and hippocampal synaptic plasticity in plaque-free Tg2576 mice. J Alzheimers Dis 24(4):799-816.

Bechade C, Cantaut-Belarif Y, Bessis A (2013) Microglial control of neuronal activity. Front Cell Neurosci 7:32.

Beggiato S, Giuliani A, Sivilia S, Lorenzini L, Antonelli T, Imbimbo BP, Giardino L, Calzà L, Ferraro L (2014) CHF5074 and LY450139 
sub-acute treatments differently affect cortical extracellular glutamate levels in pre-plaque Tg2576 mice. Neuroscience 266:13-22.

Boche D, Perry VH, Nicoll JA (2013) Review: activation patterns of microglia and their identification in the human brain. Neuropathol Appl Neurobiol 39:3-18.

Branca C, Sarnico I, Ruotolo R, Lanzillotta A, Viscomi AR, Benarese M, Porrini V, Lorenzini L, Calzà L, Imbimbo BP, Ottonello S, Pizzi M (2014) Pharmacological targeting of the $\beta$-amyloid precursor protein intracellular domain. Sci Rep 4:4618.

Colton CA, Mott RT, Sharpe H, Xu Q, Van Nostrand WE, Vitek MP (2006) Expression profiles for macrophage alternative activation genes in $A D$ and in mouse models of AD. J Neuroinflammation $3: 27$.

Colton CA (2009) Heterogeneity of microglial activation in the innate immune response in the brain. J Neuroimmune Pharmacol 4(4):399-418.

Frank S, Burbach GJ, Bonin M, Walter M, Streit W, Bechmann I, Deller T (2008) TREM2 is upregulated in amyloid plaque associated microglia in aged APP23 transgenic mice. Glia 56:1438-1447.

Giuliani A, Beggiato S, Baldassarro VA, Mangano C, Giardino L, Imbimbo BP, Antonelli T, Calzà L, Ferraro L (2013) CHF5074 restores visual memory ability and pre-synaptic cortical acetylcholine release in pre-plaque Tg2576 mice. J Neurochem 124(5):613-620.

Grathwohl SA, Kalin RE, Bolmont T, Prokop S, Winkelmann G, Kaeser SA, Odenthal J, Radde R, Eldh T, Gandy S, Aguzzi A, Staufenbiel M, Mathews PM, Wolburg H, Heppner FL, Jucker M (2009) Formation and maintenance of Alzheimer's disease betaamyloid plaques in the absence of microglia. Nat Neurosci 12:1361-1363.

Green HF, Nolan YM (2012) GSK-3 mediates the release of IL-1 $\beta$, TNF- $\alpha$ and IL-10 from cortical glia. Neurochem Int 61(5):666-671.

Guerreiro R, Wojtas A, Bras J, Carrasquillo M, Rogaeva E, Majounie E, Cruchaga C, Sassi C, Kauwe JS, Younkin S, Hazrati L, Collinge J, Pocock J, Lashley T, Williams J, Lambert JC, Amouyel P, Goate A, Rademakers R, Morgan K, Powell J, St GeorgeHyslop P, Singleton A, Hardy J (2013) TREM2 variants in Alzheimer's disease. N Engl J Med 368:117-127.

Heneka MT, Sastre M, Dumitrescu-Ozimek L, Hanke A, Dewachter I, Kuiperi C, O'Banion K, Klockgether T, Van Leuven F, Landreth GE (2005) Acute treatment with the PPARgamma agonist pioglitazone and ibuprofen reduces glial inflammation and Abeta1-42 levels in APPV717l transgenic mice. Brain 128(Pt 6):1442-1453.

Hinz B, Brune K, Rau T, Pahl A (2001) Flurbiprofen enantiomers inhibit inducible nitric oxide synthase expression in RAW 264.7 macrophages. Pharm Res 18(2):151-156.

Hsiao K, Chapman P, Nilsen S, Eckman C, Harigaya Y, Younkin S, Yang F, Cole G (1996) Correlative memory deficits, Abeta elevation, and amyloid plaques in transgenic mice. Science 274(5284):99-102.

Imbimbo BP, Del Giudice E, Colavito D, D'Arrigo A, Dalle Carbonare M, Villetti G, Facchinetti F, Volta R, Pietrini V, Baroc MF, Serneels L, De Strooper B, Leon A (2007a) 1-(3',4'-Dichloro-2-fluoro[1,1'biphenyl]-4-yl)-cyclopropanecarboxylic acid (CHF5074), a novel gamma-secretase modulator, reduces brain beta-amyloid pathology in a transgenic mouse model of Alzheimer's disease without causing peripheral toxicity. J Pharmacol Exp Ther 323(3):822-830

Imbimbo BP, Del Giudice E, Cenacchi V, Volta R, Villetti G, Facchinetti F, Riccardi B, Puccini P, Moretto N, Grassi F, Ottonello S, Leon A (2007b) In vitro and in vivo profiling of CHF5022 and CHF5074: Two beta-amyloid1-42 lowering agents. Pharmacol Res 55(4):318-328.

Imbimbo BP, Hutter-Paier B, Villetti G, Facchinetti F, Cenacchi V, Volta R, Lanzillotta A, Pizzi M, Windisch M (2009) CHF5074, a novel gamma-secretase modulator, attenuates brain betaamyloid pathology and learning deficit in a mouse model of Alzheimer's disease. Br J Pharmacol 156(6):982-993.
Imbimbo BP, Solfrizzi V, Panza F (2010) Are NSAIDs useful to treat Alzheimer's disease or mild cognitive impairment? Front Aging Neurosci 21:2.

Imbimbo BP, Frigerio E, Breda M, Fiorentini F, Fernandez M, Sivilia S, Giardino L, Calzà L, Norris D, Casula D, Shenouda M (2013) Pharmacokinetics and pharmacodynamics of CHF5074 after short-term administration in healthy subjects. Alzheimer Dis Assoc Disord 27(3):278-286.

Jacobsen JS, Wu CC, Redwine JM, Comery TA, Arias R, Bowlby M, Martone R, Morrison JH, Pangalos MN, Reinhart PH, Bloom FE (2006) Early-onset behavioral and synaptic deficits in a mouse model of Alzheimer's disease. Proc Natl Acad Sci U S A 103(13):5161-5166.

Ji K, Akgul G, Wollmuth LP, Tsirka SE (2013) Microglia actively regulate the number of functional synapses. PLoS One 8(2):e56293.

Koenigsknecht-Talboo J, Landreth GE (2005) Microglial phagocytosis induced by fibrillar beta-amyloid and IgGs are differentially regulated by proinflammatory cytokines. J Neurosci 25:8240-8249.

Kotilinek LA, Westerman MA, Wang Q, Panizzon K, Lim GP, Simonyi A, Lesne S, Falinska A, Younkin LH, Younkin SG, Rowan M, Cleary J, Wallis RA, Sun GY, Cole G, Frautschy S, Anwyl R, Ashe $\mathrm{KH}$ (2008) Cyclooxygenase-2 inhibition improves amyloid-betamediated suppression of memory and synaptic plasticity. Brain 131(Pt 3):651-664.

Lanzillotta A, Sarnico I, Benarese M, Branca C, Baiguera C, HutterPaier B, Windisch M, Spano P, Imbimbo BP, Pizzi M (2011) The $\gamma$-secretase modulator CHF5074 reduces the accumulation of native hyperphosphorylated tau in a transgenic mouse model of Alzheimer's disease. J Mol Neurosci 45(1):22-31.

Lucin KM, Wyss-Coray $T$ (2009) Immune activation in brain aging and neurodegeneration: too much or too little? Neuron 64:110-122.

Martin M, Rehani K, Jope RS, Michalek SM (2005) Toll-like receptormediated cytokine production is differentially regulated by glycogen synthase kinase 3. Nat Immunol 6(8):777-784.

Martinez FO, Helming L, Gordon S (2009) Alternative activation of macrophages: an immunologic functional perspective. Annu Rev Immunol 27:451-483.

Moriguchi S, Mizoguchi Y, Tomimatsua Y, Hayashia Y, Kadowaki T, Kagamiishi Y, Katsube N, Yamamoto K, Inoue K, Watanabe S, Nabekura J, Nakanishi H (2003) Potentiation of NMDA receptormediated synaptic responses by microglia. Mol Brain Res 119:160-169.

Morihara T, Chu T, Ubeda O, Beech W, Cole GM (2002) Selective inhibition of Abeta42 production by NSAID R-enantiomers. J Neurochem 83(4):1009-1112.

Mosser DM, Edwards JP (2008) Exploring the full spectrum of macrophage activation. Nat Rev Immunol 8:958-969.

Nimmerjahn A, Kirchhoff F, Helmchen F (2005) Resting microglial cells are highly dynamic surveillants of brain parenchyma in vivo. Science 308:1314-1318.

Ogawa O, Umegaki H, Sumi D, Hayashi T, Nakamura A, Thakur NK, Yoshimura J, Endo H, Iguchi A (2000) Inhibition of inducible nitric oxide synthase gene expression by indomethacin or ibuprofen in beta-amyloid protein-stimulated $\mathrm{J} 774$ cells. Eur J Pharmacol 408(2):137-141.

Paolicelli RC, Bolasco G, Pagani F, Maggi L, Scianni M, Panzanelli P, Giustetto M, Ferreira TA, Guiducci E, Dumas L, Ragozzino D, Gross CT (2011) Synaptic pruning by microglia is necessary for normal brain development. Science 333(6048):1456-1458.

Piccio L, Buonsanti C, Mariani M, Cella M, Gilfillan S, Cross AH, Colonna M, Panina-Bordignon P (2007) Blockade of TREM-2 exacerbates experimental autoimmune encephalomyelitis. Eur $\mathrm{J}$ Immunol 37:1290-1301.

Rogers JT, Morganti JM, Bachstetter AD, Hudson CE, Peters MM, Grimmig BA, Weeber EJ, Bickford PC, Gemma C (2011) CX3CR1 deficiency leads to impairment of hippocampal cognitive function and synaptic plasticity. J Neurosci 31:16241-16250.

Ross J, Sharma S, Winston J, Nunez M, Bottini G, Franceschi M, Scarpini E, Frigerio E, Fiorentini F, Fernandez M, Sivilia S, 
Giardino L, Calza L, Norris D, Cicirello H, Casula D, Imbimbo BP (2013) CHF5074 reduces biomarkers of neuroinflammation in patients with mild cognitive impairment: a 12-week, double-blind, placebo-controlled study. Curr Alzheimer Res 10(7):742-753.

Schafer DP, Lehrman EK, Kautzman AG, Koyama R, Mardinly AR, Yamasaki R, Ransohoff RM, Greenberg ME, Barres BA, Stevens B (2012) Microglia sculpt postnatal neural circuits in an activity and complement dependent manner. Neuron 74(4):691-705.

Sierra A, Encinas JM, Deudero JJ, Chancey JH, Enikolopov G, Overstreet-Wadiche LS, Tsirka SE, Maletic-Savatic M (2010) Microglia shape adult hippocampal neurogenesis through apoptosis-coupled phagocytosis. Cell Stem Cell 7(4):483-495.

Sivilia S, Lorenzini L, Giuliani A, Gusciglio M, Fernandez M, Baldassarro VA, Mangano C, Ferraro L, Pietrini V, Baroc MF, Viscomi AR, Ottonello S, Villetti G, Imbimbo BP, Calzà L, Giardino $L$ (2013) Multi-target action of the novel anti-Alzheimer compound CHF5074: in vivo study of long term treatment in Tg2576 mice. BMC Neurosci 14:44.

Sogn CJ, Puchades M, Gundersen V (2013) Rare contacts between synapses and microglial processes containing high levels of Iba1 and actin-a postembedding immunogold study in the healthy rat brain. Eur J Neurosci 38(1):2030-2040.

Stratman NC, Carter DB, Sethy VH (1997) Ibuprofen: effect on inducible nitric oxide synthase. Brain Res Mol Brain Res 50(1-2):107-112.

Takahashi K, Prinz M, Stagi M, Chechneva O, Neumann H (2007) TREM2-transduced myeloid precursors mediate nervous tissue debris clearance and facilitate recovery in an animal model of multiple sclerosis. PLoS Med 4(4):e124.
The Alzheimer's Disease Anti-inflammatory Prevention Trial Research Group (2013) Results of a follow-up study to the randomized Alzheimer's Disease Anti-inflammatory Prevention Trial (ADAPT). Alzheimers Dement 9(6):714-723.

Town T, Nikolic V, Tan J (2005) The microglial "activation" continuum: from innate to adaptive responses. J Neuroinflammation 2:24.

Tremblay ME, Lowery RL, Majewska AK (2010) Microglial interactions with synapses are modulated by visual experience. PLoS Biol 8(11):e1000527.

Tremblay ME, Zettel ML, Ison JR, Allen PD, Majewska AK (2012) Effects of aging and sensory loss on glial cells in mouse visual and auditory cortices. Glia 60(4):541-558.

Wake H, Moorhouse AJ, Jinno S, Kohsaka S, Nabekura J (2009) Resting microglia directly monitor the functional state of synapses in vivo and determine the fate of ischemic terminals. J Neurosci 29(13):3974-3980.

Zhan Y, Paolicelli RC, Sforazzini F, Weinhard L, Bolasco G, Pagani F, Vyssotski AL, Bifone A, Gozzi A, Ragozzino D, Gross CT (2014) Deficient neuron-microglia signaling results in impaired functional brain connectivity and social behavior. Nat Neurosci 17(3):400-406.

Zhang B, Gaiteri C, Bodea LG, Wang Z, McElwee J, Podtelezhnikov AA, Zhang C, Xie T, Tran L, Dobrin R, Fluder E, Clurman B, Melquist S, Narayanan M, Suver C, Shah H, Mahajan M, Gillis T, Mysore J, Macdonald ME, Lamb JR, Bennett DA, Molony C, Stone DJ, Gudnason V, Myers AJ, Schadt EE, Neumann H, Zhu $\mathrm{J}$, Emilsson V (2013) Integrated systems approach identifies genetic nodes and networks in late-onset Alzheimer's disease. Cell 153(3):707-720. 